\title{
Implicações Sociais, Econômicas e Ambientais de Uma Iniciativa de Manejo Florestal Comunitário em Assentamento na Amazônia Oriental ${ }^{1,2}$
}

\author{
Roberto Porro ${ }^{3}$, Noemi Sakiara Miyasaka Porro ${ }^{4}$, \\ Orlando dos Santos Watrin ${ }^{5}$, Helder do Nascimento Assunção ${ }^{6}$ e \\ Cezário Ferreira dos Santos Junior ${ }^{7}$
}

Resumo: Este estudo buscou analisar as conexões entre a participação em manejo florestal comunitário (MFC) e as variáveis mobilidade, renda e desmatamento. O trabalho foi conduzido na região da rodovia Transamazônica, no Projeto de Desenvolvimento Sustentável (PDS) Virola-Jatobá, em Anapu (PA), onde o MFC tem sido, desde 2006, uma das principais propostas do governo para conter o desmatamento, coibir a rotatividade ocupacional dos lotes e melhorar a renda. A análise de uma iniciativa de manejo florestal através de acordo empresa-comunidade indica que recursos derivados da venda de madeira não foram suficientes para conter a mobilidade espacial, reduzir o desmatamento e garantir a manutenção de meios de vida locais. Observações diretas em pesquisa-ação, de cunho antropológico, indicam que o MFC só será bem-sucedido se resultar de ação coletiva minimamente congregando os diversos e divergentes segmentos sociais do PDS. Identificou-se a resiliência de determinadas normas sociais locais em torno do cultivo da roça, como instituição camponesa, com potencial de gerar ação coletiva, inclusive para o manejo florestal. Considerando-se a diversidade de atores e a complexidade de contextos, conclui-se que o ajuste dessas normas sociais locais articulando a produção agrícola com o manejo florestal é condição essencial para a efetividade do MFC e de uma reforma agrária ambientalmente diferenciada.

Palavras-chaves: Anapu, campesinato amazônico, mobilidade espacial, desmatamento, projeto de desenvolvimento sustentável.

1. Data de submissão: 12 de outubro de 2016. Data de aceite: 24 de fevereiro de 2018.

2. Os autores agradecem à Embrapa Amazônia Oriental, à Fundação Amazônia de Amparo a Estudos e Pesquisas e ao Conselho de Pesquisas Sueco pelo apoio financeiro para a elaboração deste trabalho.

3. Embrapa Amazônia Oriental. Belém, Pará, Brasil. E-mail: roberto.porro@embrapa.br

4. Universidade Federal do Pará. Belém, Pará, Brasil. E-mail: noemi@ufpa.br

5. Embrapa Amazônia Oriental. Belém, Pará, Brasil. E-mail: orlando.watrin@embrapa.br

6. Universidade Federal do Pará. Belém, Pará, Brasil. E-mail: helnascimento@yahoo.com.br

7. Universidade Federal do Pará. Belém, Pará, Brasil. E-mail: agrosantos01@gmail.com 


\begin{abstract}
This study aimed to understand the connections among participation in community forest management (CFM), plot turnover, household income and deforestation. The empirical research was carried out in an environmentally focused land reform settlement near the Transamazon highway, the Virola-Jatobá Sustainable Development Project (PDS) in the municipality of Anapu, Pará state, Brazil. In this settlement, CFM has been for over a decade a major governmental instrument to curb deforestation, avoid land turnover and improve income. Our analysis of a community-company agreement for forest management shows that resources derived from the sale of timber were unable to reduce spatial mobility, control deforestation and provide sustainable livelihoods. Direct observation in anthropological action research shows that CFM will only succeed if resulting from collective action assembling the diverse and divergent social groups in the PDS. We also identified that specific social norms related to swidden, slash-and-burn fields have the potential to generate collective action, even towards forest management. Considering the local diversity of actors and complexity of contexts, we conclude that the adjustment of social norms connecting swidden fields to forest management is a critical condition for the effectiveness of CFM and the environmental land reform modality.
\end{abstract}

Key-words: Anapu, Amazon peasantry, spatial mobility, deforestation, sustainable development project.

Classificação JEL: Q15, Q23, Q56, R14, Z13.

DOI: http://dx.doi.org/10.1590/1234-56781806-94790560405

\section{Introdução}

Apesar da diversidade que caracteriza os campesinatos amazônicos, o cultivo das roças tradicionais de corte e queima representa uma das únicas alternativas agroecológicas para camponeses nas primeiras fases de instalação em áreas florestadas. No bojo de esforços governamentais para adequação ambiental que visam reduzir as taxas de desmatamento e o uso do fogo na Amazônia, estes camponeses, que detêm o conhecimento tradicional de uso da terra e os recursos para cultivar apenas sob condições de floresta abundante, vêem-se obstruídos em seus argumentos que justificam a manutenção do cultivo da roça como instituição fundamental do modo de vida que os caracteriza. $\mathrm{O}$ manejo florestal sustentável apresenta-se, então, como alternativa a este segmento do campesinato amazônico, que nos últimos anos se depara com normativas ambientais cada vez mais restritivas.

Tal situação afeta diretamente beneficiários de programas de reforma agrária na Amazônia, para quem a legislação ambiental tem se constituído em fator adicional de propulsão da já elevada taxa de mobilidade espacial (DE SARTRE et al., 2016; LUDEWIGS, 2006). Desde sua concepção em 1999, devido à ênfase ambiental, os chamados Projetos de Desenvolvimento Sustentável (PDS) contrastam com os Projetos de Assentamento (PA) convencionais. O PDS caracteriza-se pelo regime comunal de posse da área de Reserva Legal, emitida a partir de Contrato de Concessão de Direito Real de Uso (CCDRU) em nome de uma ou mais associações que congreguem as famílias assentadas (MDA/INCRA, 2006). Dentre as modalidades de reforma agrária implementadas na Amazônia (ALENCAR et al., 2016; LE TOURNEAU e BURSZTYN, 2010), o PDS proporcionaria condições para iniciativas de manejo florestal comunitário que contribuiriam para geração de renda, meios de vida locais e sustentabilidade ambiental. Neste artigo, o estudo detalhado da trajetória de assentamento, das atividades econômicas e do uso da terra em um PDS visa compreender o efeito de uma iniciativa de manejo florestal comunitário em aspectos sociais (mobilidade espacial), econômicos (renda familiar) e ambientais (desflorestamento).

No contexto estudado, o PDS Anapu III e IV, designado como PDS Virola-Jatobá (PDS-VJ), são registradas diferenças marcantes na adoção de estratégias de sobrevivência entre segmentos do campesinato ali residente, influenciando fortemente as variáveis enfocadas neste estudo. Embora ainda recente, o histórico de acontecimentos que marca a ocupação do PDS-VJ, inclusive a condução de uma iniciativa de manejo florestal comunitário através de acordo com empresa madeireira, tem fragilizado meios de vida locais e impedido a consolidação de normas sociais em comunidades camponesas em formação. Tal cenário se deve sobretudo à 
atuação inconsistente do Estado que resulta na colisão entre direitos sociais e ambientais (BENATTI, 1999), retardando tanto o alcance de metas de justiça agrária quanto as de conservação ambiental.

Através do estudo de caso do PDS Virola-Jatobá, analisam-se fatores com potencial de delinear uma categorização social, e que estão associados à permanência de famílias em seus lotes, mesmo sob condições restritivas. Desprovidos em sua grande parte de capital, lidando com normas oficiais que praticamente inviabilizam a transformação da terra em ativo de valor sob sua própria concepção, os camponeses têm sua capacidade de trabalho na roça limitada pelas imposições ambientais. Em consonância com a literatura que aborda dinâmicas agrárias em frente pioneira (REYNAL et al., 1995; SABOURIN, 2011), múltiplos fatores têm favorecido a saída de assentados do PDS-VJ de seus lotes, e muitas famílias efetivamente seguem essa tendência. Contudo, registra-se que outros permanecem. Neste artigo, busca-se compreender o efeito da iniciativa de manejo florestal para a saída ou permanência no lote, sob a ótica destes segmentos camponeses. Procura-se ainda demonstrar que, mesmo sob fortes condicionantes, camponeses que adotam estratégias distintas para definir seus meios de vida podem conviver em uma área de assentamento com ênfase ambiental, se mantidos os institutos de reciprocidade e autonomia ${ }^{8}$ que os definem enquanto camponeses, via de regra gerados pelas relações sociais estabelecidas no cultivo da roça.

Neste estudo argumenta-se que, em um PDS, iniciativas de manejo florestal comunitário somente serão viáveis se ajustadas às normas sociais internas, construídas e negociadas pelos diversos grupos, sob as condições concretas da modalidade fundiária. Observações empíricas indicam que a convivência propiciada pela atividade agrícola na roça contribui para essa constituição coletiva de normas. Responder sobre até que ponto estas normas permitirão a convivência entre grupos de famílias camponesas, mesmo considerando-se sua diversidade e complexidade, dependerá da forma através da qual serão mantidos

8. Considera-se o cultivo da roça como instituição fundante do campesinato na Transamazônica, sustentada por institutos de autonomia no controle dos meios de produção da unidade familiar e de reciprocidade entre unidades familiares de produção e consumo (SHANIN, 1995; GUZMÁN e MOLINA, 2006; GODOI et al., 2009). os atuais níveis de controle por parte do Estado. Além disso, as normas só serão efetivas se as organizações locais lograrem consolidar mecanismos internos para sua implementação. Um exemplo de normas para gestão e governança sobre a terra e recursos naturais associados é o Plano de Uso do assentamento, debatido, negociado e votado somente em 2016 pelos diferentes grupos do PDS, após anos de trâmites. Mesmo aprovado e sancionado pelo Incra, as famílias deparam-se com dificuldades para consolidar os mecanismos necessários para implementá-lo.

\section{Contexto}

O Projeto de Desenvolvimento Sustentável (PDS) constitui uma modalidade ambientalmente diferenciada de Reforma Agrária, que permite a prática da agricultura familiar, extrativismo e atividades de baixo impacto ambiental. Enquanto instrumento de regularização fundiária, o PDS surge com a Portaria Incra no 477/1999, modificada pela Portaria no 1040/2002, que contempla agricultores familiares cuja experiência de trabalho anterior não fosse necessariamente a atividade extrativa. A proposta chamou a atenção de organizações governamentais e não governamentais porque, distinto das Reservas Extrativistas, possibilita que grupos sociais não necessariamente designados como tradicionais ${ }^{9}$ também acessem áreas com relevante cobertura florestal, sob premissas de conservação ${ }^{10}$.

Em cada PDS existem Áreas de Reserva Legal (ARL) e Áreas de Uso Alternativo (AUA), além das APPs (Áreas de Preservação Permanente), que podem ocorrer no interior de ambas. A ARL em PDS somente pode ser utilizada de forma coletiva, através de planos de manejo florestal sustentável aprovados pelos órgãos ambientais, no caso a Secretaria Estadual de Meio Ambiente e Sustentabilidade (Semas-Pará). Já a AUA é explorada sob regime familiar, usualmente em lotes de 20 ha para uso de cada família beneficiária.

9. Para uma distinção entre as diversas formas de relação entre distintos grupos sociais e o ecossistema em que vivem, ver Lima e Pozzobom (2005).

10. A criação de Projetos de Assentamento em áreas com cobertura florestal primária passou a ser regulada pela Lei no 11.284 de fevereiro de 2006, que rege o uso de florestas públicas. 
626 - Implicações Sociais, Econômicas e Ambientais de Uma Iniciativa de Manejo Florestal Comunitário em Assentamento na Amazônia Oriental

Localizados na microrregião de Altamira, estado do Pará, os PDS do município de Anapu incluem o PDS Anapu I, designado como PDS Esperança, ao sul da rodovia Transamazônica com terras mais férteis, e o PDS Anapu III e IV, designado como PDS Virola-Jatobá (PDS-VJ), ao norte da rodovia, com terras menos férteis. No caso de Anapu, a opção por esse instrumento diferenciado deveu-se, sobretudo na fase inicial, ao trabalho realizado pela religiosa Dorothy Stang e à Comissão Pastoral da Terra, que idealizaram essa proposta que articula a reforma agrária à conservação ambiental na chamada região da rodovia Transamazônica (MENDES, 2015; PORRO et al., 2015).

Contudo, antagonismos sociais, cuja expressão mais visível é simbolizada pelo assassinato de Dorothy Stang em 2005, provocaram desdobramentos que, mesmo passada uma década, ainda influenciam as perspectivas daqueles interessados na posse e no uso daquelas terras. A área onde foi criado o PDS-VJ consiste de um mosaico de glebas de cerca três mil hectares, anteriormente destinadas a empreendedores rurais que, nas décadas de 1980 e 1990, assinaram, mas não cumpriram as cláusulas de contratos de alienação de terras públicas (CATP), sendo a terra restituída à União.

Criado pela Portaria SR01 no 39/2002 (INCRA, 2016), o PDS Virola-Jatobá compreende dois módulos distintos, atualmente ocupando um total de 39.602 hectares. As sete glebas do PDS Anapu III, totalizando 24.519 ha, são integralmente definidas como Reserva Legal (RL), enquanto no PDS Anapu IV estão localizadas cinco glebas (de números 107, 128, 129, 130 e 136), totalizando $15.083 \mathrm{ha}$, onde além do restante da RL do PDS, situam-se 160 lotes de uso alternativo (AUA) (Figura 1). Tais lotes correspondem a parcelas de tamanho médio de 20 hectares, originalmente destinadas ao uso agropecuário pelas famílias assentadas. Contudo,

Figura 1. Localização das glebas do PDS Virola-Jatobá

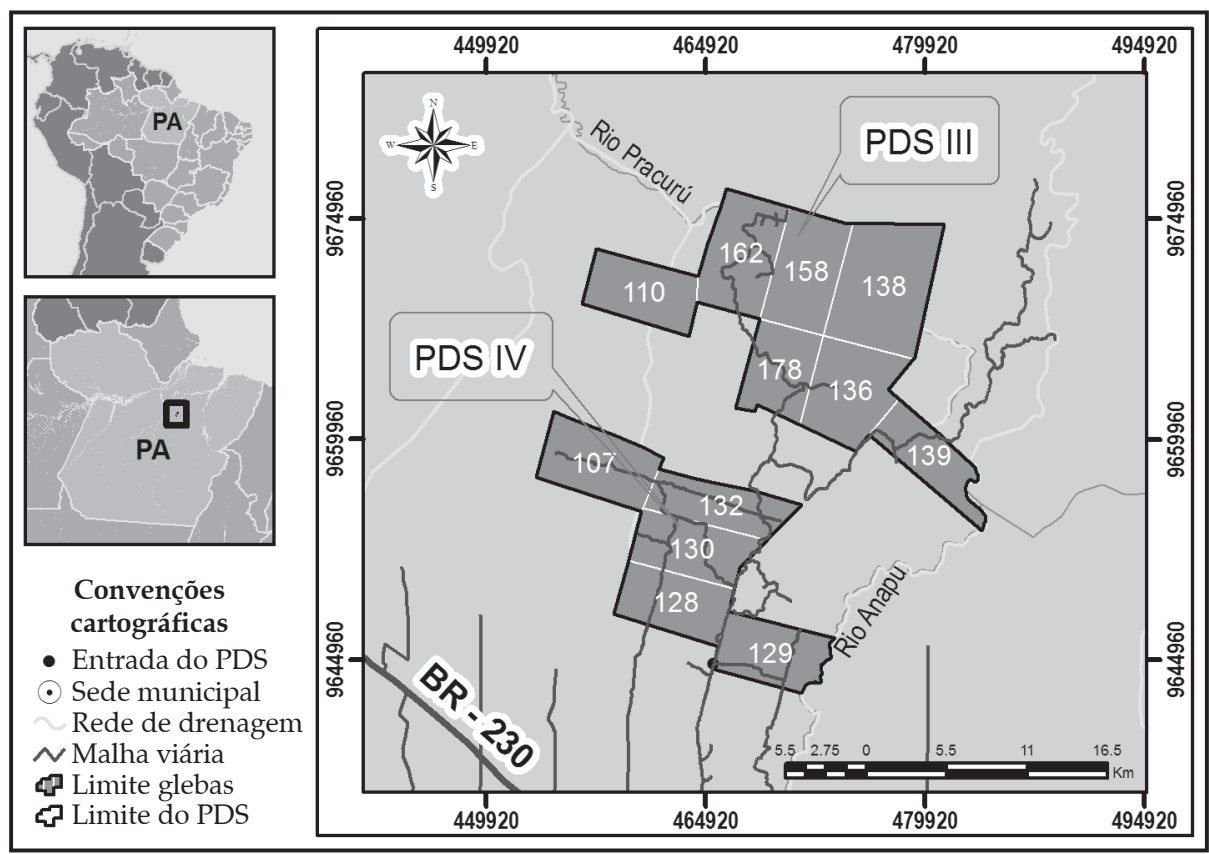

Fonte: Projeto Automanejo, Embrapa Amazônia Oriental (2016) 
medidas de controle do desmatamento na Amazônia ${ }^{11}$ e no estado do Pará12 resultaram em procedimentos mais rígidos para a obtenção de autorizações de supressão florestal, notadamente nos municípios que não cumpriram com metas dos acordos estabelecidos, visando a redução do desmatamento, como é o caso de Anapu.

O maior rigor na aplicação da legislação ambiental faz com que a própria noção de área de uso alternativo (AUA), adotada pelo Incra no momento da instalação das famílias na terra quando da criação do PDS, passasse a ser descaracterizada. $\mathrm{Na}$ implantação do PDS, lotes para uso familiar foram distribuídos a ocupantes que teriam autonomia para utilizá-los integralmente na produção agropecuária (exceto onde neles houver APPs), desde que seguindo normas estabelecidas por um Plano de Uso a ser definido pelos assentados. Porém, com a aprovação do novo Código Florestal Brasileiro (Lei no 12.651, de 25.05.2012), a supressão de vegetação nativa para uso alternativo do solo passa a depender de prévia autorização do órgão ambiental estadual, e áreas antropizadas após julho de 2008 passam a ser tratadas como infração ambiental que demanda recomposição. Constatou-se que, desde o estabelecimento do PDS, a obtenção das autorizações de supressão para uso agrícola mostrou-se impraticável dada a incapacidade dos próprios órgãos em definir responsabilidades e viabilizar mecanismos para o licenciamento, situação que perdura até o presente.

Por outro lado, as características do ambiente biofísico do PDS-VJ não privilegiam a agricultura voltada ao mercado, corroborando a vocação do PDS para a produção extrativa que resulte na comercialização de produtos florestais. As famílias do PDS-VJ envolvidas

11. O Decreto no 6.321 de 21.12.2007 estabeleceu ações para prevenir, monitorar e controlar o desmatamento ilegal na Amazônia, criando a Lista de Municípios Prioritários, nos quais são priorizadas medidas de integração e aperfeiçoamento das ações de monitoramento e controle de órgãos federais, o ordenamento fundiário e territorial e o incentivo a atividades econômicas ambientalmente sustentáveis.

12. O Decreto Estadual no 54/2011 criou o Programa Municípios Verdes, e uma série de Instruções Normativas da Semas vem definindo procedimentos administrativos para a realização de limpeza e autorização de supressão nas áreas de vegetação secundária em estágio inicial de regeneração, desde que localizadas fora da Reserva Legal e da Área de Preservação Permanente dos imóveis rurais, no âmbito do estado do Pará, a exemplo da IN 08 de 28.10.2015 da Semas. em ação coletiva em torno desse enfoque são atualmente representadas pela Associação Virola Jatobá do PDS Anapu (AVJ) e pela Cooperativa de Produtores Agrícolas Orgânicos Florestais do PDS Virola-Jatobá (Coopaf). Assim, neste artigo, será tomado o PDS-VJ como estudo de caso e a AVJ e a Coopaf como protagonistas para a compreensão quanto ao papel do manejo florestal como estratégia do campesinato para geração de renda, e quanto à efetividade desta estratégia para de alguma forma consolidar a ocupação dos lotes pelas famílias assentadas e reduzir a mobilidade.

O PDS-VJ apresenta aspectos que tenderiam a processos de ocupação observados historicamente em outras localidades de fronteira na Amazônia (VELHO, 1972), nas quais, à abertura inicial por famílias descapitalizadas, segue-se a saída dos ocupantes pioneiros para terras de valor inferior, geralmente mais distantes, dotadas de menos infraestrutura e ainda sob cobertura florestal. Tal saída muitas vezes associa-se a processos de concentração fundiária. No caso estudado, contudo, aceitando a heterogeneidade e complexidade como aspectos a serem considerados e não evitados (POTEETE e OSTROM, 2004; GODOI et al., 2009), registra-se que não é o esgotamento dos recursos disponíveis que leva ao abandono do lote. Ademais, nos casos de abandono, a cessão de direitos de uso do lote para terceiros tende a ocorrer entre iguais.

A análise da mobilidade de assentados nos lotes do PDS-VJ até 2015 indica que, especialmente até 2014, havia maior ênfase na aplicação de normativas fundiárias pelo Posto Avançado do Incra em Anapu. Reconhecendo a AVJ como legítima representante dos assentados, a atuação do Incra dificultou a negociação de lotes para pecuaristas ou produtores capitalizados, assim como a acumulação de mais de um lote por ocupante. Os PDS não proporcionam a seus ocupantes a titulação da terra, e sim contratos de concessão de uso, ao contrário do que ocorre nas demais modalidades fundiárias da região (lotes da antiga colonização, projetos de assentamento convencionais, e áreas devolutas tituladas a partir do Programa Terra Legal do então Ministério do Desenvolvimento Agrário). Tais restrições, somadas ao maior rigor na aplicação dos critérios de assentamento ${ }^{13}$, devido ao histórico de formação do

13. Contudo, os critérios de seleção dos chamados candidatos a cliente de reforma agrária convencional não são necessariamente suficientes para a seleção eficiente de candidatos a assentados em PDS. 
628 - Implicações Sociais, Econômicas e Ambientais de Uma Iniciativa de Manejo Florestal Comunitário em Assentamento na Amazônia Oriental

PDS, delimitariam o universo de ocupantes a quem tais terras são acessíveis.

A partir de 2002, o assentamento de famílias nos lotes do PDS-VJ ocorre ao longo de estradas vicinais que cortam as mencionadas glebas. O histórico desse assentamento e a cronologia diferenciada de regularização efetiva de cada gleba mostrou-se determinante no delineamento da diversidade de atores locais. Ao longo dos anos, práticas de organização social adotadas pelas famílias assentadas utilizaram como critério de agrupamento a distribuição espacial ao longo das vicinais e glebas do PDS. Neste artigo, tal distribuição constituirá uma das variáveis de análise, pois tanto o instituto da reciprocidade quanto o de autonomia foram influenciados e influenciaram a conformação e composição de grupos de vizinhança e parentesco. Dessa forma, a organização espacial das famílias é relevante para a constituição de normas sociais internas e, consequentemente, ao potencial de ação coletiva.

\section{Métodos}

Os dados obtidos para a elaboração deste artigo resultam de atividades de campo dos autores em projeto de pesquisa iniciado em julho de 2014, cujo objetivo consiste em avaliar os impactos sociais, econômicos e ambientais do acordo contratual mantido entre a comunidade e uma empresa para a execução de manejo florestal, rompido após cinco anos devido a irregularidades. A pesquisa também visa analisar cenários para a retomada deste manejo, mas com governança local.

O contrato em questão, assinado em junho de 2007 e com validade de 15 anos, considerava unidades de produção anuais de até 1.000 ha. Os inventários florestais seriam executados pela AVJ, que também participaria no romaneio (controle da volumetria a ser transportada). O contrato estabelecia que a empresa exploraria todas as espécies selecionadas no inventário, e comprometer-se-ia a obter a certificação pelo Forest Stewardship Council (FSC) em até cinco anos. A empresa efetuaria pagamentos à AVJ de acordo com a produção transportada. Os pagamentos seriam baseados em preços revisados anualmente para espécies classificadas em cinco categorias. A empresa proporcionaria formação profissional para os residentes do PDS, e gradualmente os empregaria nas atividades de exploração. Em cinco anos, esses postos deveriam atingir até $40 \%$ do pessoal empregado pela empresa nas operações locais. Uma parcela de $10 \%$ do volume de madeira de cada unidade anual de produção seria reservada para processamento local. Além disso, a empresa era responsável pela manutenção e conservação da infraestrutura viária para acessar a área de manejo florestal, e por fornecer vigilância e monitoramento contra a invasão e exploração madeireira ilegal no PDS. Por fim, o instrumento excluía a subcontratação de terceiros sem autorização prévia da AVJ. Devido a irregularidades na gestão de planos de manejo por empresas na Amazônia, em dezembro de 2010 o Incra estabeleceu um prazo de dois anos para o encerramento de contratos como o estabelecido no PDS-VJ, que, portanto, deixou de vigorar em dezembro de 2012.

Viagens a campo entre agosto de 2014 e dezembro de 2015 permitiram estabelecer uma rotina de pesquisa-ação (THIOLLENT, 2013) que integrava a coleta de dados etnográficos e quantitativos, com a inserção em demandas das organizações locais (associação e cooperativa) para acessar políticas públicas, e particularmente reestabelecer as ações de manejo florestal. Contudo, os procedimentos de análise pela Semas dos planos operacionais anuais incluíam a verificação rigorosa do uso da terra não apenas na área do Plano de Manejo, mas em todo o assentamento. Desta forma, ao longo da pesquisa-ação, constatou-se que o envolvimento das famílias assentadas no manejo florestal demandava ações articuladas para viabilizar também o licenciamento dos roçados, e a consequente supressão florestal para estes cultivos. Na sequência, apresenta-se as principais variáveis e os métodos associados à obtenção dos dados analisados neste artigo.

\subsection{Mobilidade espacial}

Famílias sem experiência com as condições do ecossistema local, sem assistência técnica e crédito adequado, e sem o vínculo e o apoio mútuo de uma comunidade, deparam-se com menor probabilidade de consolidar seu assentamento. Tal conjugação tem causado intensa mobilidade no PDS Virola-Jatobá, a exemplo do observado em outros assentamentos amazônicos (CAMPARI, 2002, 2005; LUDEWIGS et al., 2009). Nesta pesquisa, a condição de ocupação de cada um dos 160 lotes do PDS foi registrada e associada a variáveis espaciais. Os registros da ocupação sequen- 
cial destes estabelecimentos (espaços de domínio de unidades familiares), desde a criação do assentamento até o final de 2015, foram obtidos a partir de consulta à base de dados do Incra (relação de beneficiários em diferentes anos, e cadastros detalhados de cada ocupante atual). Outras informações derivaram de entrevistas com seis informantes-chaves locais, assentados pioneiros que residiam no PDS desde os anos iniciais de seu estabelecimento, conhecedores da sequência de ocupação dos lotes nas glebas em que residem. Tais informações incluíram o período de residência no lote por cada ocupante e a condição de formalização do assentado. Para esta variável, classificaram-se as famílias residentes como (1) assentados pelo Incra e em relação de beneficiários (RB), e (2) ocupantes ainda não formalmente assentados. Já para a frequência de ocupação nos lotes, foram estabelecidas três categorias, considerando-se o período de 2002 a $2015^{14}$ : (a) Rotatividade Baixa (um a dois ocupantes no lote), (b) Rotatividade Média (três a quatro ocupantes), (c) Rotatividade Alta (cinco ocupantes ou mais).

Nota-se que, até o final de 2013, a RB era frequentemente atualizada pelo Incra, acompanhando a dinâmica de ocupação dos lotes, sobre a qual havia maior controle por parte tanto do órgão fundiário como pela Associação AVJ. Embora reconhecendo não estar em conformidade com procedimentos formais da política de assentamento, o órgão muitas vezes adotou a prática de validar a saída de famílias que negociavam suas benfeitorias a terceiros, que passavam, então, a fazer parte da RB. Contudo, a partir de 2014, e especialmente de 2015, a RB passa a ter lapsos cada vez maiores em sua atualização, o que coincide com a intensificação da ocupação de lotes à revelia do Incra e da AVJ.

\subsection{Renda familiar}

Um levantamento socioeconômico foi aplicado em julho de 2015, abrangendo 76 (88\%) das 86 famílias regularmente assentadas no PDS Virola-Jatobá pelo Incra. Não foram entrevistados os ocupantes de 57 lotes em situação irregular perante o Incra, enquanto 13 lotes estavam desocupados na ocasião, e quatro lotes eram considerados comunitários. As dez famílias restantes não foram localizadas ou negaram-se a

14. Também foram observadas situações de lotes alocados para uso comunitário e lotes nunca ocupados. responder o questionário, que incluía sessões sobre demografia, uso da terra, cultivos, benfeitorias e bens, consumo e fontes de renda da família. Após a realização das entrevistas, os dados digitados foram revisados e exportados ao programa estatístico STATA, no qual as análises foram realizadas. Para este artigo, foram analisados dados das sessões sobre renda familiar e uso da terra. O questionário continha perguntas sobre que atividades geraram renda monetária para o domicílio nos últimos 12 meses, e o respectivo rendimento. Para captar a diversidade do campesinato em relação à estratégia de produção, uma tipologia (GARCIA FILHO et al., 1997) composta por seis categorias (tipos) foi construída a partir de limiares de rendimento em relação ao total da renda monetária familiar, indicando a dependência de determinada fonte. A categoria 'agroextrativista' integra famílias com $50 \%$ ou mais de sua renda derivada da integração da produção agrícola, criação de pequenos animais e produtos florestais. Na categoria 'pecuarista', ao menos $50 \%$ da renda anual familiar provém da venda de bovinos ou seus produtos (leite e queijo). A categoria 'diarista' agrega famílias com ao menos $50 \%$ de sua renda advinda de diárias de trabalho. A categoria 'empregados e funcionários' refere-se a famílias com a maior parte da renda derivada de salário não rural (como é o caso de professores e funcionários da prefeitura municipal). Aqueles que dependem em mais de $50 \%$ de aposentadorias, pensões e transferências sociais do governo foram designados na categoria 'aposentados e assistidos'. Por fim, a categoria 'diversificado' inclui famílias cuja renda integrava produtos agroextrativistas, diárias e transferências sociais, sem forte predominância de uma destas fontes.

\subsection{Desmatamento}

As informações relativas ao desflorestamento na área de estudo foram obtidas pelo Laboratório de Sensoriamento Remoto da Embrapa Amazônia Oriental, a partir da construção de base de dados espaciais na plataforma SPRING 5.3 (INPE/DPI 2015). A base de dados no sistema de projeção SIRGAS 2000 foi estruturada por meio de produto cartográfico do IBGE, derivado para a escala 1:50.000, tendo como balizadores o limite e a grade fundiária do PDS, delineados pelo mapa digital do imóvel cedido pelo Incra. Para o mapeamento dos padrões de uso e cobertura da terra foram empregadas imagens Landsat, órbita/ponto 225/62, nas 
630 - Implicações Sociais, Econômicas e Ambientais de Uma Iniciativa de Manejo Florestal Comunitário em Assentamento na Amazônia Oriental

datas de 17/06/2002 (bandas TM 3, 4 e 5) e 15/07/2015 (bandas OLI 4, 5 e 6), já ortorretificadas e com correção atmosférica, obtidas gratuitamente a partir de USGS (2015). As imagens selecionadas foram classificadas a partir de método supervisionado por regiões, considerando o algoritmo Bhattacharya, como descrito por Watrin et al. (2009). Os produtos temáticos preliminares foram analisados em levantamento de campo e posteriormente submetidos a edições temáticas de modo a reduzir erros de classificação. As imagens temáticas geradas foram manipuladas em ambiente ArcGIS 10.1 (ESRI, 2015) de modo a definir apenas duas classes: Floresta e Área Desflorestada, sendo esta última obtida pelo agrupamento das classes capoeira, pastagem, agricultura e queimada. Considerando como unidade de análise a área dos lotes definida pela grade fundiária do PDS, foi possível realizar análises espaciais para qualificação do desflorestamento nos mesmos. A análise do desmatamento nos lotes não está, portanto, associada aos ocupantes atuais, mas sim à sucessão de ocupantes que, desde a criação do PDS, eram os responsáveis pelos lotes da AUA. A integração de dados sobre rotatividade de ocupação permitiu analisar a associação do nível de desflorestamento do lote com a variável que indica o total de ocupantes que residiu em cada lote desde a criação do PDS, bem como a intensidade da mobilidade de ocupantes em cada um dos espaços considerados.

\subsection{Uso da terra}

Neste artigo, as classes de uso da terra referem-se à informação declarada em levantamento realizado entre maio e outubro de 2015. Na entrevista, cada assentado foi solicitado a responder a área de seu estabelecimento de acordo com 12 classes de uso e cobertura da terra, que para esta análise foram agrupadas em apenas cinco, conforme apresentado: (1) cultivos anuais (roça atual e palhada do ano anterior); (2) cultivos perenes (cacau, pimenta e pomar doméstico); (3) capoeiras (fina: entre dois e cinco anos, média: entre seis e dez anos e grossa: entre 11 e 20 anos); (4) pastagem (pasto limpo e sujo); (5) floresta natural (terra firme, alagada e vegetação secundária com mais de 20 anos). A área total de cada lote foi calculada com base na grade fundiária disponibilizada pelo Incra, observando-se significativa variância quanto à média de 20 ha, preconizada como padrão para os lotes de uso alternativo, sob regime familiar no PDS. Uma vez que no início do assentamento a área dos lotes estava em sua quase totalidade coberta por florestas, a área restante foi classificada como floresta.

\section{Resultados e discussão}

\subsection{Mobilidade nos lotes de uso alternativo}

A Tabela 1 apresenta o resultado da análise do número de ocupantes de cada um dos lotes do PDS Virola-Jatobá, distribuídos pelas quatro glebas onde os mesmos estão localizados. Chama a atenção a elevada taxa de mobilidade em um período de apenas 13 anos, numa média de 3,3 famílias sucedendo-se em cada lote, o que resulta em um total de 533 famílias, que ocuparam pelo menos um lote desde o estabelecimento do PDS. Excluídos os ocupantes que saíram dos lotes inicialmente recebidos, mas que se mudaram para outros lotes do PDS-VJ, temos 468 ocupantes únicos. Dos 158 lotes analisados ${ }^{15}, 51(33,1 \%), 64(40,0 \%)$ e $43(26,9 \%)$ apresentavam taxas de mobilidade com intensidades respectivamente baixa, média e alta. Como resultado desta elevada mobilidade e da falta de atualização da Relação de Beneficiários a partir de 2014, o número de famílias formalmente assentadas e inseridas na RB do Incra era apenas pouco superior à metade do número de lotes $(53,8 \%)$ ao final de 2015.

A dinâmica de ocupação de famílias nos lotes do PDS Virola-Jatobá pode ser observada pelo gráfico da Figura 2, que representa o fluxo praticamente contínuo de entrada e saída de famílias desde 2002.

Observa-se que, embora o ano de maior entrada de famílias tenha sido 2004, o período de 2008 a 2010 mostra significativo influxo de novos ocupantes, retomado em 2015. Por outro lado, desde a criação do PDS, os dados indicam média anual de evasão de cerca $20 \%$ dos lotes habitados, que pouco reduziu-se mesmo durante os anos em que vigorava o projeto de manejo florestal (2008-2012). Nestes anos, a associação repassou valores ao redor de $\mathrm{R} \$ 3.000$ por ano a praticamente todas as famílias então residentes no PDS, o que poderia estimular a permanência dos assentados. Demonstra-se, portanto, que, na situação con-

15. Dos 160 lotes de uso alternativo, dois lotes comunitários nunca habitados foram excluídos da análise. 
Tabela 1. Frequência e condição de ocupantes por lote e gleba no PDS Virola-Jatobá, Anapu

\begin{tabular}{|c|c|c|c|c|c|c|c|c|c|c|}
\hline & \multicolumn{10}{|c|}{ Agrupamento } \\
\hline & \multicolumn{2}{|c|}{ G129 } & \multicolumn{2}{|c|}{ G128-130 } & \multicolumn{2}{|c|}{ G107 } & \multicolumn{2}{|c|}{ G132 } & \multicolumn{2}{|c|}{ Total } \\
\hline & $n$ & $\%$ & $n$ & $\%$ & $n$ & $\%$ & $n$ & $\%$ & $n$ & $\%$ \\
\hline \multicolumn{11}{|l|}{ a. Condição de ocupação do lote } \\
\hline Ocupados por famílias em RB & 26 & 59,1 & 27 & 84,4 & 17 & 44,7 & 16 & 34,8 & 86 & 53,8 \\
\hline Ocupados por famílias fora de RB & 17 & 38,6 & 4 & 12,5 & 8 & 21,1 & 28 & 60,9 & 57 & 35,6 \\
\hline Lotes comunitários & 1 & 2,3 & 1 & 3,1 & 0 & 0 & 2 & 4,3 & 4 & 2,5 \\
\hline Lotes vagos & 0 & 0 & 0 & 0 & 13 & 34,2 & 0 & 0 & 13 & 8,1 \\
\hline Total de lotes & 44 & & 32 & & 38 & & 46 & & 160 & \\
\hline \multicolumn{11}{|l|}{ b. Número de ocupantes / lote } \\
\hline Baixa mobilidade (1-2) & 12 & 27,3 & 16 & 53,1 & 19 & 50,0 & 4 & 10,9 & 51 & 33,1 \\
\hline Média mobilidade (3-4) & 13 & 29,5 & 11 & 34,4 & 13 & 34,2 & 27 & 58,7 & 64 & 40,0 \\
\hline Alta mobilidade (5-9) & 19 & 43,2 & 4 & 12,5 & 6 & 15,8 & 14 & 30,4 & 43 & 26,9 \\
\hline \multicolumn{11}{|l|}{ c. Total de ocupantes } \\
\hline Número de ocupantes por gleba & 168 & & 88 & & 103 & & 174 & & 533 & \\
\hline Ocupantes que mudaram de lote & 15 & & 9 & & 24 & & 17 & & 65 & \\
\hline Universo de ocupantes únicos & 153 & & 79 & & 79 & & 157 & & 468 & \\
\hline Média de ocupantes por lote & 3,8 & & 2,8 & & 2,7 & & 3,8 & & 3,3 & \\
\hline
\end{tabular}

Fonte: Base de dados do Posto Avançado do Incra-Anapu; Projeto Automanejo, Embrapa Amazônia Oriental (2015).

Figura 2. Dinâmica de entrada e saída de famílias no PDS Virola-Jatobá (2002-2015)

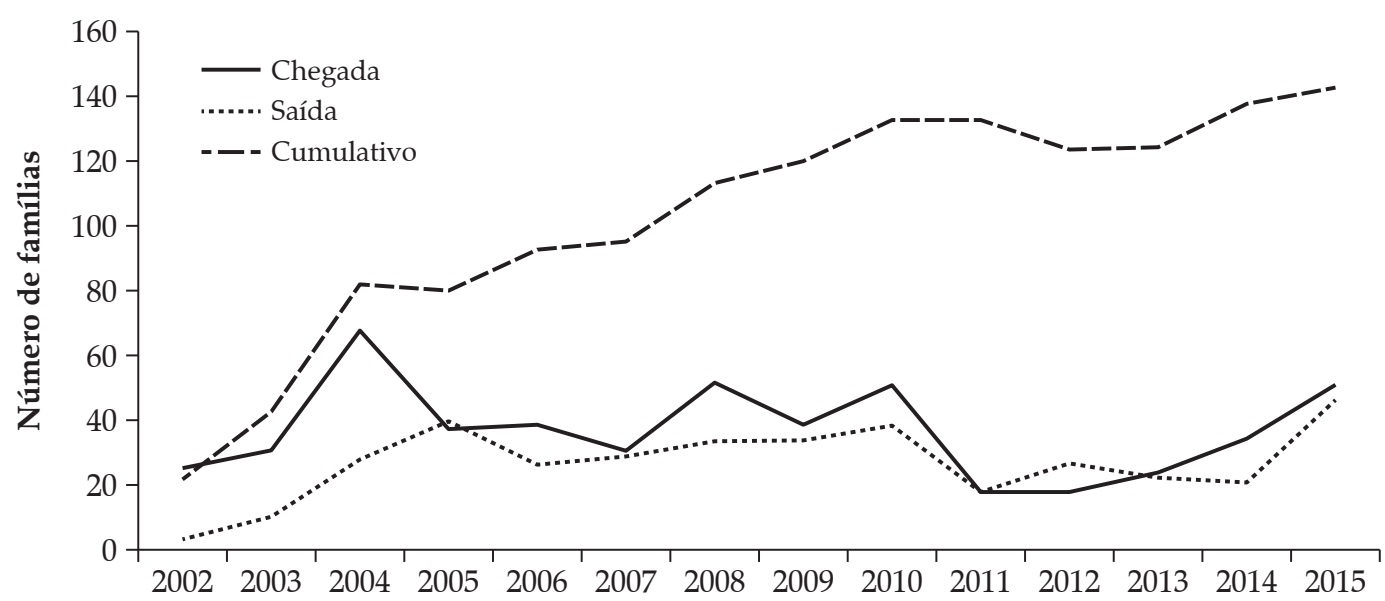

Fonte: Projeto Automanejo, Embrapa Amazônia Oriental (2016)

creta do PDS-VJ, ao se aplicar o formato proposto pelo governo, através do Ibama - Promanejo, os resultados do manejo florestal não foram suficientes para modificar o padrão de mobilidade, o que será examinado na próxima sessão.

Os registros e relatos obtidos em campo permitem também avaliar o peso da influência da localização do lote sobre o tempo médio de permanência das famílias residentes. Considerando-se o total de 517 ocupantes para os quais há registro de chegada e saída no PDS, o tempo médio desta permanência limita-se a dois anos e meio. Tal média, contudo, mascara diferenças espaciais significativas. Tomando-se os quatro agrupamentos apresentados na Tabela 1, enquanto as Glebas 107 e 129 apresentam tempos médios de permanência equivalentes à média geral, o tempo de permanência é superior nas Glebas 128-130 (quatro anos), onde após a instabilidade da primeira fase de ocupação, a rotatividade diminui em função da instalação de agricultores com projetos familiares de permanência. Por outro 
632 - Implicações Sociais, Econômicas e Ambientais de Uma Iniciativa de Manejo Florestal Comunitário em Assentamento na Amazônia Oriental

lado, o oposto ocorre na Gleba 132 (1,6 ano), onde vive a maioria daqueles que, chamados de novatos, buscam sobretudo associar-se à atividade pecuária.

\subsection{Renda florestal, mobilidade e estratégias de produção}

A alta taxa de mobilidade dos assentados indica a existência de fortes pressões para a saída de famílias do PDS, exemplificadas pela falta de ação efetiva do Estado, a aplicação da legislação ambiental, e a insegurança quanto à possibilidade de venda futura de benfeitorias por elas incorporadas na terra. Porém, a seção anterior demonstrou que determinados segmentos sociais do conjunto são afetados diferentemente por essas pressões. A permanência na condição de assentado de PDS implica na identificação de relações sociais e condições para a produção que geram oportunidades que se contrapõem a estas pressões para viabilizar a manutenção da família. Tais oportunidades são normalmente expressas através de iniciativas econômicas, de caráter individual ou coletivo.

O sentimento de pertencimento a um contexto que, embora ainda recente, aglutina socialmente indivíduos que compartilham normas sociais semelhantes, contribui, portanto, para manter o interesse na permanência através de ações coletivas para enfrentar essas pressões. Segundo as famílias pioneiras, tais normas seriam aquelas associadas à proposta original daqueles que vivenciaram a fundação do PDS enquanto modalidade ambientalmente diferenciada de reforma agrária. Embora tivessem oportunidades de intercâmbio e soubessem das enormes dificuldades enfrentadas por outros grupos no Acre e na Flona Tapajós ${ }^{16}$, as lideranças representantes dessas famílias optaram por investir na busca pelo manejo florestal comunitário (MFC) associado às roças, como estratégia econômica a possibilitar sua permanência no lote, de forma sustentável. Na perspectiva desse grupo, cabe a esse coletivo identificar elementos que concorrem efetivamente para esta permanência, para que outros compartilhem dessas normas e passem a se engajar no MFC enquanto ação coletiva.

16. Dificuldades e evidências de baixo retorno da atividade florestal por agricultores familiares foram analisadas por Sist et al. (2010), Medina e Pokorny (2011), Sablayrolles et al. (2011) e Piketty et al. (2015).
Esta sessão integra a análise da mobilidade no PDS com dados relativos à distribuição de recursos provenientes da ação coletiva em torno do MFC, possibilitada a partir de acordo entre a Associação Virola-Jatobá e uma empresa madeireira, que até então constituiu-se na principal iniciativa econômica associada à proposta do PDS-VJ. Para avaliar a relevância da receita gerada pelo manejo florestal, a mesma será analisada comparativamente com dados de levantamento socioeconômico realizado em 2015.

As atividades de MFC no PDS-VJ foram conduzidas entre 2008 e 2012. Trata-se de manejo florestal pleno, ou seja, com metas de exploração de até $30 \mathrm{~m}^{3}$ de madeira por hectare, mas cujo instrumento de execução, o Plano de Manejo Florestal Sustentável (PMFS), tem como detentor uma comunidade, através de sua associação (Associação Virola Jatobá, AVJ). Para efeito de exploração florestal, a AVJ havia assinado em 2008 um contrato de 15 anos com a empresa Vitória Régia $\mathrm{S} / \mathrm{A}$. Conforme mencionado, o encerramento do contrato foi forçado pela Instrução Normativa 65 do Incra, que buscava barrar os danos derivados de má conduta de empresas, que via de regra desrespeitavam normas sociais, econômicas e ambientais na exploração florestal em áreas de projetos de assentamento de reforma agrária. Ainda assim, durante 2013, a empresa obteve autorização do órgão ambiental estadual para transportar o volume restante de cerca $9.000 \mathrm{~m}^{3}$ de madeira explorada em 2012, mas não retirada da área devido ao período chuvoso ${ }^{17}$.

Consultas aos arquivos da Associação Virola Jatobá permitiram a análise detalhada da distribuição dos recursos provenientes do manejo florestal durante os seis anos em que a atividade gerou renda para a associação, num montante total superior a R\$ 3,9 milhões, referente à venda de mais de $51 \mathrm{mil} \mathrm{m}^{3}$ de madeira ${ }^{18}$. A análise focalizou particularmente o período de 2010 a 2013, durante o qual foram realizados rateios, ou distribuição dos valores da madeira para as famílias assentadas. $\mathrm{O}$ regimento interno definido pela AVJ determinava que, do valor bruto recebido como pagamento da madeira retirada pela empresa, 55\% seriam

17. Para uma análise detalhada da condução deste manejo florestal e dos impactos dele derivados na organização social do PDS-Virola Jatobá, vide Porro et al. (2015).

18. Ao longo do contrato, a empresa pagou à associação o valor médio de $\mathrm{R} \$ 80,16$ por $\mathrm{m}^{3}$ de madeira efetivamente extraída. 
distribuídos entre os sócios residentes há pelo menos um ano no PDS, em condição regular de assentado perante o Incra. $\mathrm{O}$ restante $(45 \%)$ seria aplicado em benefícios comuns para a AVJ, e no custeio administrativo da exploração por parte da mesma.

Como pode ser observado na Tabela 2 , a receita proveniente da madeira do primeiro Plano Operativo Anual (POA 2008) foi integralmente utilizada em benefícios comuns e no custeio administrativo. Tal fato ocorreu devido a que, em 2008, parte considerável dos assentados, especialmente os pioneiros que viviam na vicinal 120, não estava em situação regular perante o Incra, pois pendências judiciais impediam a anexação formal das Glebas 128, 129 e 130 ao PDS, o que somente ocorreu em 2009. Por esta razão, o rateio para sócios passou a vigorar apenas a partir do segundo POA, ocorrido em 2009 e, mesmo assim, somente após forte pressão das famílias assentadas junto ao Ministério Público Federal, que naquele período mediou as condições que regiam o contrato de manejo. No total, ocorreram cinco episódios de distribuição de renda derivada do manejo florestal: POA 2009 (junho de 2010), POA 2010 (maio de 2011 e fevereiro de 2012), POA 2012 (dezembro de 2012 e dezembro de 2013). A Figura 3 identifica o número de famílias contempladas e o volume de recursos destinado através de rateio, qualificando esta distribuição conforme a condição de permanência ou saída da família.

Tabela 2. Receita da venda de madeira do PDS Virola-Jatobá e montante rateado às famílias

\begin{tabular}{|c|c|c|c|c|c|c|c|}
\hline & \multicolumn{7}{|c|}{ Data do rateio de recursos } \\
\hline & 2008 & 6.2010 & 5.2011 & 2.2012 & 12.2012 & 12.2013 & Total \\
\hline POA / UPA & $2 / 2008$ & $3 / 2009$ & $4 / 2010$ & $4 / 2010$ & $5 / 2012$ & $5 / 2012$ & \\
\hline Área da UPA (ha) & 501 & 505 & 973 & ** & 1.090 & $* *$ & 3.068 \\
\hline Madeira extraída $\left(\mathrm{m}^{3}\right)$ & 4.112 & 10.481 & 10.423 & 5.400 & 10.386 & 10.386 & 51.189 \\
\hline Total pago à AVJ (R\$) & 267.311 & 738.240 & 826.764 & 319.861 & 882.838 & 882.838 & 3.917 .853 \\
\hline Valor distribuído (R\$) & 0 & 441.500 & 465.500 & 179.650 & 377.010 & 299.320 & 1.762 .980 \\
\hline INPC cumulativo até 6.2015 & - & $37,97 \%$ & $30,53 \%$ & $26,57 \%$ & $19,75 \%$ & $13,44 \%$ & \\
\hline Total ajustado pelo INPC (R\$) & - & 609.138 & 607.617 & 227.383 & 451.469 & 339.549 & 2.235 .156 \\
\hline Famílias beneficiadas & - & 125 & 131 & 128 & 120 & 116 & 124 \\
\hline Total ajustado (R\$/família) & - & 4.873 & 4.638 & 1.776 & 3.762 & 2.927 & \\
\hline Valor médio distribuído (R\$/ano) & & & & & & & 558.789 \\
\hline Valor médio recebido (R\$/família/ano) & & & & & & & 4.506 \\
\hline
\end{tabular}

Fonte: Projeto Automanejo, Embrapa Amazônia Oriental (2015).

Figura 3. (a) Número de famílias contempladas pelos recursos provenientes do MFC em relação à permanência ou ao ano em que saíram do PDS. (b) Volume de recursos recebidos pelas famílias em relação à permanência ou ao ano em que saíram do PDS

(a)

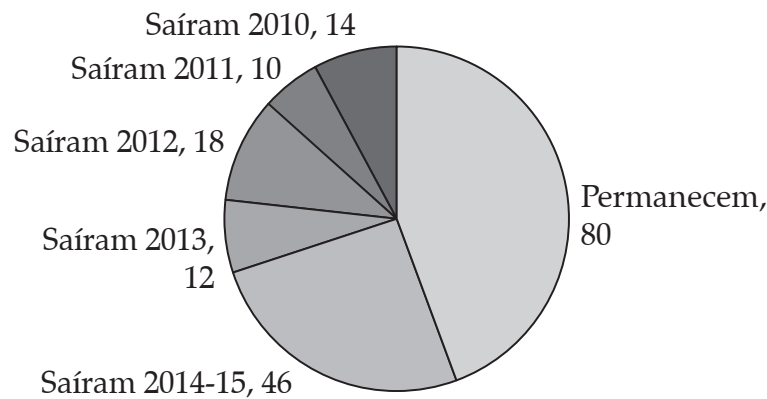

(b)

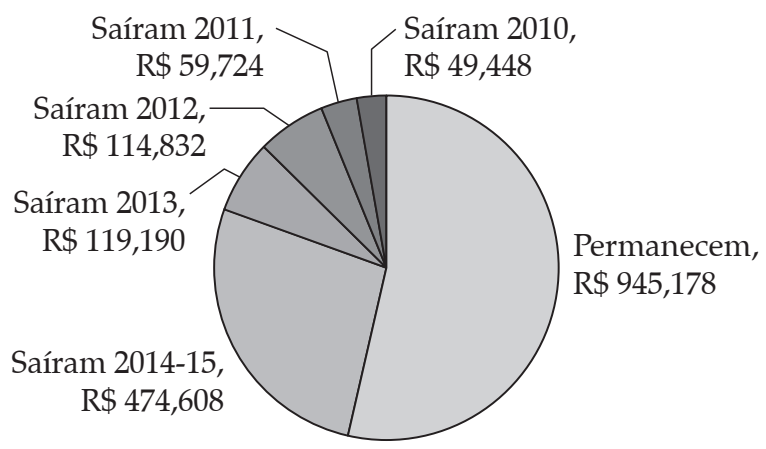

Fonte: Projeto Automanejo, Embrapa Amazônia Oriental (2015). 
634 - Implicações Sociais, Econômicas e Ambientais de Uma Iniciativa de Manejo Florestal Comunitário em Assentamento na Amazônia Oriental

Entre 2010 e 2013 o valor total de R\$ 1.762 .980 foi distribuído a 180 famílias. Destas, contudo, apenas $44 \%$ (80 famílias) permaneciam no PDS em dezembro de 2015. Conforme já examinado, uma média anual de 28 famílias deixava o PDS, mas esse total incluía famílias de permanência curta, que não foram contempladas com recursos do MFC. Contudo, durante a vigência do plano de manejo, um número significativo de famílias contempladas com recursos oriundos da madeira deixou o PDS, mesmo quando se esperava a continuidade do manejo nos anos seguintes. Tal fato ocorreu com 14, 10, 18 e 12 famílias, respectivamente, em 2010, 2011, 2012 e 2013. Outras 46 famílias contempladas deixaram o PDS após o encerramento do acordo com a empresa, em 2014 e 2015. Das 180 famílias contempladas pelo manejo florestal, apenas 70 participaram dos cinco rateios, sendo que 21 destas deixaram o PDS após 2013. Esses dados indicam que o aporte de recursos recebido do MFC, pelo menos no montante possibilitado pelo acordo, e considerando a modalidade de manejo em parceria com empresa, não foi suficiente para deter a mobilidade dos camponeses.

Em termos financeiros, famílias que em dezembro de 2015 permaneciam assentadas no PDS-VJ receberam apenas pouco mais da metade $(53,6 \%)$ dos recursos provenientes da exploração florestal nos cinco rateios realizados. Conforme apresentado na Tabela 2, entre 2010 e 2013, o valor anual médio total de R\$ 558.789 (ajustado pelo INPC para junho de 2015) foi rateado a 124 famílias (em média, a cada ano), cabendo a cada uma destas o valor médio (ajustado) de R\$ 4.506 no total dos cinco rateios.

Para dimensionar a relevância da renda proporcionada pelo manejo florestal aos residentes no PDS, foram comparados os valores distribuídos às famílias nos cinco episódios de rateio, com a renda informada em 2015 por ocasião da aplicação dos questionários a 76 famílias. A análise dos questionários indica que, nos 12 meses que antecederam o levantamento, tais famílias haviam obtido receita de $\mathrm{R} \$ 594.155$. A Tabela 3 apresenta a renda obtida pelas famílias considerando sua fonte de origem.

Pode ser observado que, dentre os itens informados como fontes de receita monetária, a maior contribuição era dos repasses sociais do governo (aposentadorias, pensões e programas de distribuição de renda, como o Bolsa Família), representando mais de $28 \%$ do total. Quando deduzido este item do total (uma vez que tais pagamentos independem da vigência ou não do manejo florestal no conjunto das rendas advindas de atividades produtivas), a renda anual gerada ( $\mathrm{R} \$ 426.452)$ corresponde a uma receita anual média de R\$ 5.611 para cada família. O valor anualmente recebido pelas famílias durante os quatro anos em que ocorreu o rateio de recursos oriundos do manejo florestal equivaleria, portanto, a mais de $80 \%$ do valor da soma de todas as receitas monetárias advindas de atividades produtivas dos assentados no PDS, constituindo $45 \%$ da renda total oriunda do lote.

Cabe destacar que muitos assentados trabalharam e foram remunerados diretamente pela empresa durante a vigência do manejo florestal, ou foram pagos pela associação a partir dos repasses recebidos pela venda das toras nos pátios do PDS-VJ. Se fossem contabilizados esses valores, tal renda elevaria substancialmente o valor total gerado pelo manejo florestal. Contudo, uma atividade que assegurava receita tão significativa para a economia familiar, e que ainda por

Tabela 3. Renda anual (R\$) de famílias assentadas no PDS Virola-Jatobá estimada para 2015

\begin{tabular}{lcccccc}
\hline \multicolumn{1}{c}{ Fonte de renda } & $\mathbf{n}$ & Média & Mediana & DV. padrão & Soma & $\%$ \\
\hline Agricultura & 46 & 2.189 & 915 & 3.294 & 100.681 & 16,9 \\
Pequenos animais & 28 & 1.294 & 800 & 1.593 & 36.218 & 6,1 \\
Floresta & 15 & 734 & 600 & 701 & 11.011 & 1,9 \\
Bovinos & 6 & 8.967 & 1.900 & 12.508 & 53.800 & 9,1 \\
Diárias & 38 & 1.991 & 1.300 & 3.034 & 75.645 & 12,7 \\
Salário não rural & 17 & 7.854 & 8.880 & 4.431 & 133.522 & 22,5 \\
Programas sociais & 45 & 3.727 & 2.400 & 3.497 & 167.703 & 28,2 \\
Outras & 10 & 1.558 & 1.425 & 959 & 15.575 & 2,6 \\
Renda total & 76 & 7.818 & 5.301 & 6.757 & 594.155 & 100,0 \\
\hline
\end{tabular}

Fonte: Projeto Automanejo, Embrapa Amazônia Oriental (2015). 
cima não demandava o envolvimento direto dos assentados em sua execução, não foi suficiente para limitar a saída de famílias do PDS-VJ. Para melhor compreender a lógica e motivação dos que permaneceram no PDS, na sequência será analisado o perfil econômico destas famílias, com base na contribuição relativa das fontes geradoras de renda familiar.

Aplicando a tipologia construída para definir o perfil econômico das famílias assentadas, pela Tabela 4 pode-se observar que, passados 13 anos do início do PDS, famílias que permanecem no assentamento apresentaram perfis distintos, atestando a necessidade de considerar a diversidade como fator relevante nessa análise. Tais perfis e sua representação no PDS incluem: (a) aqueles que efetivamente podem ser considerados como produtores agroextrativistas (e cuja renda derivada da agricultura neste caso é bastante superior àquela originada da criação de pequenos animais e de produtos da floresta); (b) uma minoria de pecuaristas com renda anual mais elevada; (c) um grupo mais numeroso de famílias com menor nível de renda, predominantemente dedicados a trabalho como diarista rural, ou (d) aqueles cujos ingressos são diversificados entre diárias e agricultura e extrativismo familiar. Além destes, dois grupos apresentam rendas monetárias anuais similares que, embora baixas, são muito superiores àquelas auferidas pelos diaristas: (e) famílias com renda derivada de salários em empregos públicos ou trabalho não vinculado à produção rural, como comércio; e (f) aposentados e assistidos por programas sociais de transferência de renda.

A aplicação do teste estatístico de Bonferroni para comparar a renda média anual entre estes grupos (Tabela 5) indica significância para valores superiores auferidos por pecuaristas em comparação com as demais categorias, e da renda anual mais alta de funcionários quando comparados a diaristas.

À época da pesquisa de campo, constatamos que era comum a saída de famílias que repassavam seus direitos por valores oscilando entre 2 e 5 mil reais, semelhante, portanto à receita média anual das famílias de renda mais baixa no PDS. Num contexto agrário de alta rotatividade ocupacional, um componente fundamental da renda familiar pode vir a ser exatamente o diferencial de valor do lote realizado entre ocupação e saída. No caso do PDS-VJ, para assentados que recebiam um lote com custo de ocupação bastante reduzido, a alternativa de repassar adiante este lote com as benfeitorias nele instaladas, e sobretudo o direito de vir a ser eventualmente beneficiado por ações futuras

Tabela 4. Renda anual (em R\$) conforme perfil econômico das famílias assentadas no PDS Virola-Jatobá

\begin{tabular}{lcccccc}
\hline \multicolumn{1}{c}{ Categoria } & $\mathbf{n}$ & $\boldsymbol{\%}$ & Média & Mediana & DV. padrão & Soma \\
\hline a) Agroextrativistas & 18 & 23,7 & 7.223 & 5.165 & 5.670 & 130.008 \\
b) Pecuaristas & 3 & 3,9 & 22.582 & 32.724 & 18.401 & 67.746 \\
c) Diaristas & 19 & 25,0 & 4.112 & 2.580 & 4.765 & 78.121 \\
d) Agroextrativista-diaristas & 8 & 10,5 & 4.631 & 4.766 & 2.119 & 37.051 \\
e) Assalariados & 13 & 17,1 & 11.428 & 11.488 & 5.152 & 148.564 \\
f) Aposentados/assistidos & 15 & 19,7 & 8.844 & 8.724 & 4.265 & 132.665 \\
Total & 76 & 100,0 & 7.818 & 5.301 & 6.757 & 594.155 \\
\hline
\end{tabular}

Fonte: Projeto Automanejo, Embrapa Amazônia Oriental (2015).

Tabela 5. Análise da renda dos assentados do PDS-VJ conforme tipologia de estratégias econômicas

\begin{tabular}{|c|c|c|c|c|c|}
\hline & Agroextrativista & Pecuarista & Diarista & Funcionário & Aposentado \\
\hline Pecuarista & $15,359^{* * *}$ & & & & \\
\hline Diarista & $-3,111$ & $-18,470^{* * *}$ & & & \\
\hline Assalariado & 4,205 & $-11,154^{* *}$ & $7,316^{* * *}$ & & \\
\hline Aposentado & 1,622 & $-13,738^{* * *}$ & 4,733 & $-2,584$ & \\
\hline Diária \& agricultura & $-2,591$ & $-17,951^{* * *}$ & 0,520 & $-6,797$ & $-4,213$ \\
\hline $\mathrm{F}=7,43 \quad$ Prob $>F$ & 0000 & & & & \\
\hline
\end{tabular}

Fonte: Projeto Automanejo, Embrapa Amazônia Oriental (2016). 
636 - Implicações Sociais, Econômicas e Ambientais de Uma Iniciativa de Manejo Florestal Comunitário em Assentamento na Amazônia Oriental

de assentamento, mostrava-se alternativa plausível, embora o valor auferido dificilmente superasse a receita anual média obtida pela família caso permanecesse no lote, ainda mais durante a vigência da exploração florestal, quando o valor recebido pelo rateio da madeira praticamente duplicava a renda familiar anual.

\subsection{Desmatamento e uso da terra}

Esta seção analisa as consequências da configuração econômica nos padrões de desmatamento e uso da terra, e na relação destes padrões com a mobilidade de famílias no lote. A área dos lotes destinados ao uso alternativo (cerca de 20 ha por família) no PDS-VJ totaliza 3.411 ha. Deste total, no ano de criação do PDS (2002), ou seja, anterior à entrada das famílias assentadas, haviam sido classificadas como áreas desflorestadas apenas 158,2 ha (4,6\% do total), em oposição à área observada em 2015, onde foram registrados 1.318 ha de áreas desflorestadas (38,6\% do total). Assim, como pode ser observado na Figura 4, o desflorestamento nos lotes ao longo de 13 anos aumentou 547\%. De fato, em 2002, o desflorestamento resultava nulo em 89,5\% dos lotes estudados (143 entre 160). Os lotes com desflorestamento moderado e alto localizavam-se ao longo da vicinal 120, na porção oeste da Gleba 129, próximos da entrada principal do PDS.

Com exceção de lotes ocupados por pecuaristas relativamente capitalizados, o desmatamento decorre da roça anual, e sua ampliação depende sobretudo do tempo de ocupação do lote. É assim necessário relacionar a localização do desmatamento com este tempo de ocupação. No PDS-VJ, a ocupação dos lotes ocorreu a partir de 2002, exceto na faixa transversal da Gleba 129, onde a abertura da estrada e demarcação de lotes ocorreu em 2006. Em 2015, é visível a dispersão do desflorestamento por todas as glebas, porém com maior concentração exatamente nas Glebas 129 e 132. Comparativamente, a gleba menos impactada é a 107, cujos lotes foram demarcados e ocupados desde o início do assentamento. Porém, por esta gleba ser a mais distante da entrada do PDS e, por conseguinte, a mais afastada da rodovia Transamazônica, muitos de seus lotes permaneceram sem ocupante após a desistência dos primeiros assentados. Estes lotes que estavam abandonados em 2015 foram, contudo, excluídos desta análise.

Figura 4. Áreas desflorestadas observadas em 2002 e 2015 nos lotes de uso alternativo do PDS Virola-Jatobá, Anapu, PA

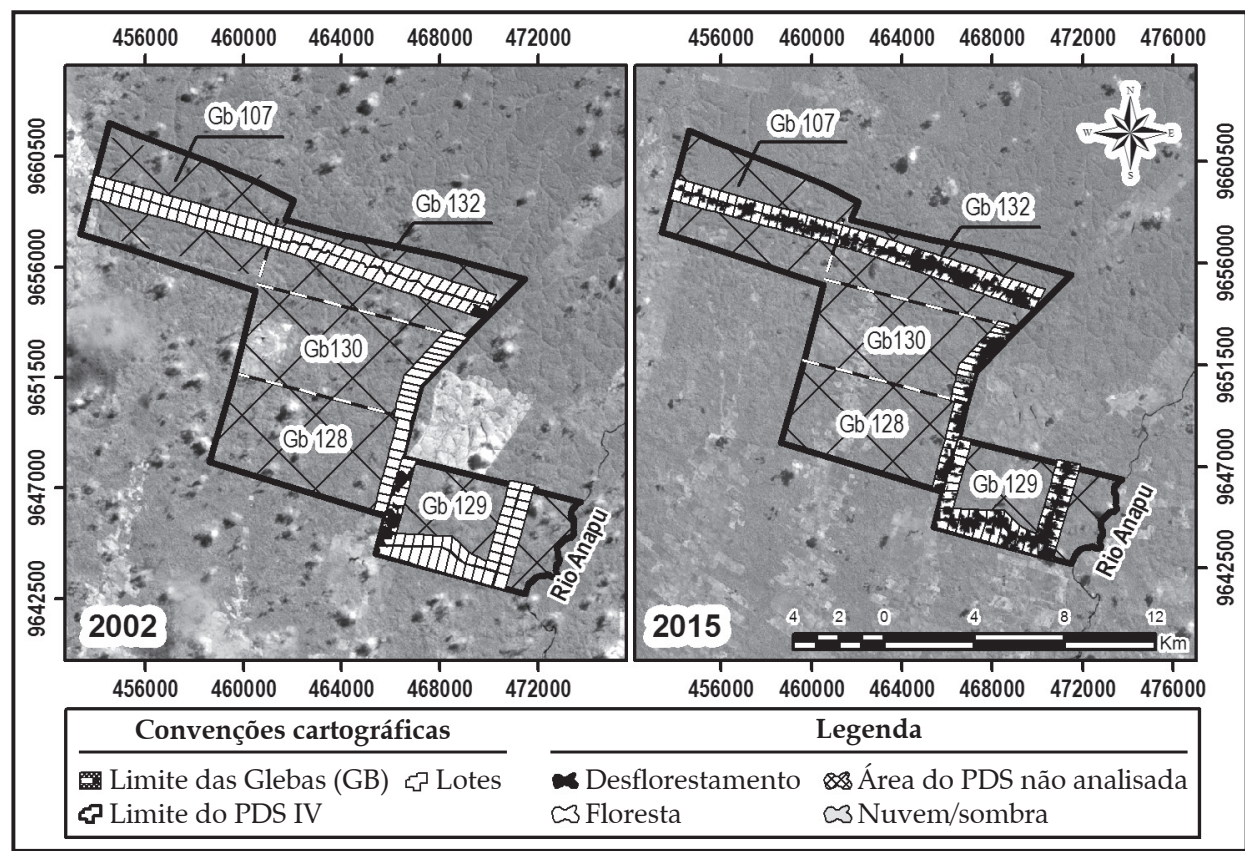

Fonte: Projeto Automanejo, Embrapa Amazônia Oriental (2016). 
Tabela 6. Relação entre desflorestamento e frequência de ocupantes nos lotes de uso alternativo no PDS Virola-Jatobá, Anapu, PA

\begin{tabular}{lccc}
\hline \multicolumn{1}{c}{ Número de ocupantes/lote } & $\mathbf{n}$ & $\begin{array}{c}\text { Área média do lote } \\
\text { (ha) }\end{array}$ & $\begin{array}{c}\text { Desflorestamento médio } \\
(\mathbf{\%})\end{array}$ \\
\hline Baixa rotatividade & 50 & 21,11 & 23,83 \\
Média rotatividade & 67 & 21,16 & 35,74 \\
Alta rotatividade & 35 & 19,63 & 34,25 \\
Total & 152 & 20,83 & 30,72 \\
\hline
\end{tabular}

Fonte: Projeto Automanejo, Embrapa Amazônia Oriental (2016).

Tabela 7. Análise estatística da relação entre desflorestamento e frequência de ocupação dos lotes de uso alternativo no PDS Virola-Jatobá, Anapu, PA

\begin{tabular}{|c|c|c|c|c|}
\hline Mobilidade & Baixa & Média & Mobilidade & Baixa \\
\hline Média & $11,9178^{* * *}$ & & Média \& Alta & $11,4052^{* * *}$ \\
\hline Alta & $10,4240^{*}$ & $-1,49377$ & & \\
\hline$F=5,23$ & Prob $>F=0,0064$ & & $F=10,40$ & Prob $>F=0,0015$ \\
\hline
\end{tabular}

${ }^{*} p<0,10 ;{ }^{* *} p<0,05 ;{ }^{* * *} p<0,01$.

Fonte: Projeto Automanejo, Embrapa Amazônia Oriental (2016).

Duas variáveis devem ser examinadas para a avaliação comparativa do desmatamento: o tempo de ocupação total dos lotes e a tipologia dos ocupantes com maior tempo de permanência no lote, pois agricultores mais capitalizados tendem a implantar roças mais extensas. Considerando que não ocorrem diferenças quanto ao tempo desde a ocupação inicial dos lotes, e adotando a tipologia de classificação dos lotes de acordo com a intensidade de mobilidade, as análises indicaram que lotes com menor número de ocupantes ao longo do tempo apresentam, em média, menor área desflorestada (Tabela 6). Quando agregados nas classes de frequência de ocupação nos lotes, tem-se que a taxa média de desflorestamento nos lotes com baixa rotatividade era de $23,8 \%$. Lotes com taxas de rotatividade média e alta apresentaram desmatamento médio de $35,7 \%$ e $34,2 \%$, respectivamente. ${ }^{19}$

O teste de Bonferroni (Tabela 7) indicou significância estatística para a afirmação de que lotes com baixa rotatividade (frequência de ocupantes não superior a duas famílias no período de dez anos) apresentam desflorestamento inferior aos demais em pelo menos $10 \%$. A análise, contudo, não indica significância estatística para diferenças na área desflorestada em lotes com

19. Nesta análise foram excluídos oito lotes (lotes comunitários, ou abandonados). mais de três ocupantes no período (lotes com média e alta rotatividade).

Como elemento final da análise e objetivando articular a ocorrência de mobilidade espacial, renda e desmatamento, estudou-se o comportamento de duas outras variáveis: finalidade de uso e tipo de cobertura da terra. Para tanto, as mesmas foram analisadas conforme a tipologia de estratégias econômicas dos assentados nos 76 lotes de uso alternativo onde foram aplicados os questionários.

A Tabela 8 e a Figura 5 apresentam a área em hectares e a porcentagem da superfície do lote reportada pelos assentados para cinco classes de uso e cobertura: floresta, capoeira, pastagem, cultivos anuais e cultivos perenes. A análise indica uma diversidade em estratégias adotadas pelas famílias, resultando em cobertura florestal média próxima a $60 \%$ para o total dos lotes, cujo tamanho médio resultou em 21,3 ha.

Cerca de 10\% do total da área estava coberta por capoeiras, percentual semelhante àquele sob cultivo agrícola (sendo $7 \%$ para anuais e mais de 3,5\% para perenes), ao passo que uma área média superior a $20 \%$ do total consistia de pastagens (embora com variação entre lotes consideravelmente maior). Destaca-se que, embora apenas seis dos entrevistados efetivamente declarassem criar gado na ocasião da entrevista, um número crescente de famílias passou a investir seu trabalho no estabelecimento de pastagens nos lotes, 
638 - Implicações Sociais, Econômicas e Ambientais de Uma Iniciativa de Manejo Florestal Comunitário em Assentamento na Amazônia Oriental

Figura 5. Percentagem de uso da terra nos lotes dos assentados no PDS Virola-Jatobá conforme tipologia de estratégias econômicas

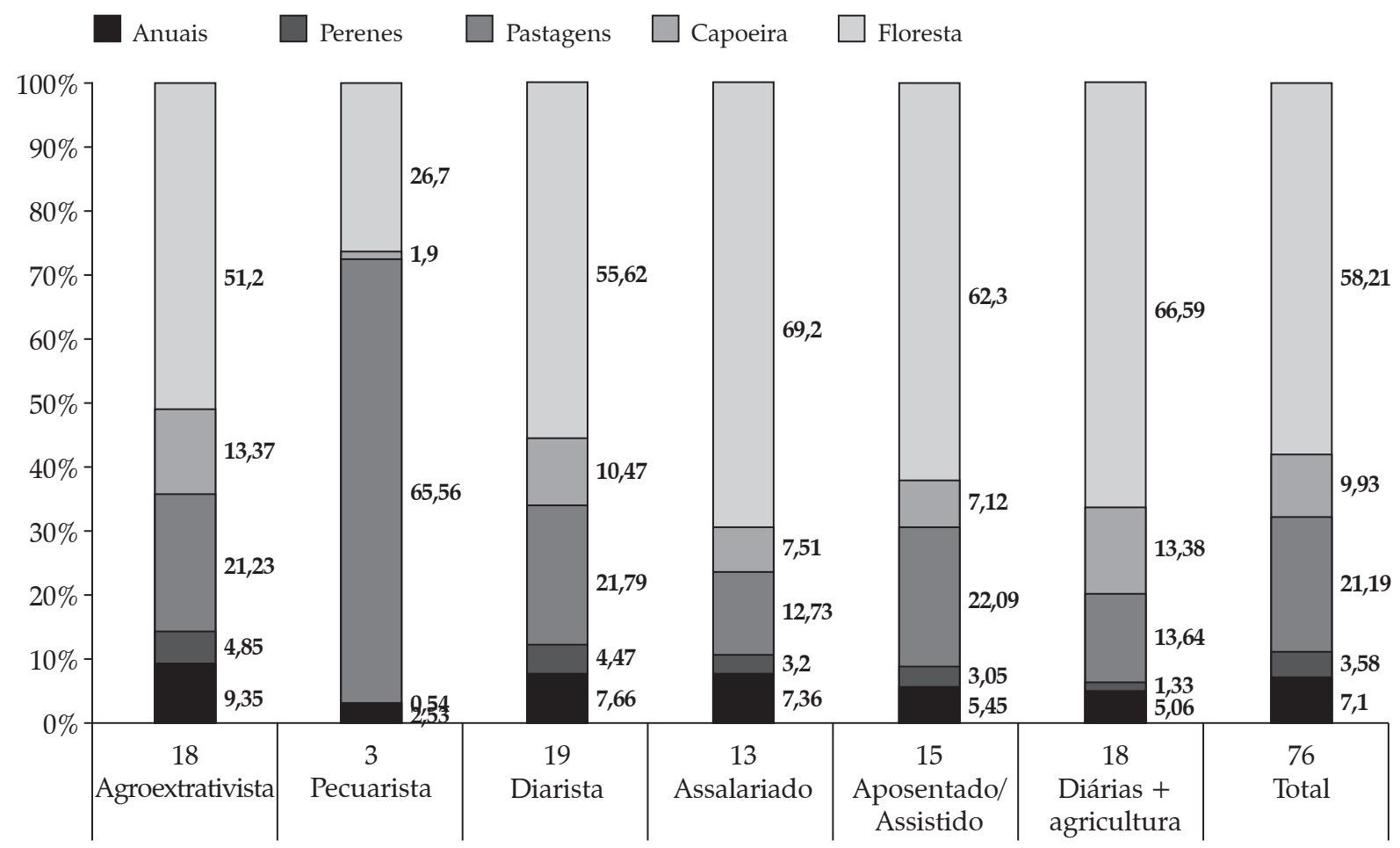

Fonte: Projeto Automanejo, Embrapa Amazônia Oriental (2016).

manifestando a intenção de, no futuro, incluir a atividade pecuária como parte de sua estratégia econômica.

A análise destes valores (Tabela 9) demonstra, como esperado, significância estatística para áreas mais extensas em pastagem nos lotes de pecuaristas, que apresentavam, em média, entre $47 \%$ e $57 \%$ mais pastagem que os demais grupos da tipologia, indicando, portanto, desmatamento consolidado. Já para as outras classes de uso da terra, os valores médios aparentemente distintos não resultaram em diferença estatisticamente significativa em nenhuma das comparações, mesmo no caso de florestas, lembrando que todos os tipos ilustrados representam segmentos que permaneceram no PDS.

A Figura 5 facilita a visualização da relação entre estratégias econômicas (renda) e cobertura da terra (desmatamento). Registra-se que pastagens representam desmatamentos consolidados, cuja expansão é mais afetada pela demanda de mercado do que outras opções. Por outro lado, cultivos anuais, perenes e capoeiras representam desmatamentos temporários e recuperação da vegetação em diferentes estágios e formações, cuja expansão e retração são mais afetados pelas necessidades de consumo da unidade familiar. Nesse sentido, nas entrevistas qualitativas, foi observado que os agroextrativistas, principalmente, mas também os demais tipos, com exceção dos pecuaristas, mantêm forte ancoragem na roça e nela exercitam a reciprocidade e autonomia. Não existem diferenças estatisticamente significativas no que se refere ao tamanho de suas roças. Os dados qualitativos de cunho etnográfico obtidos traduzem que a roça é uma instituição camponesa que persiste mesmo em assentamentos com ênfase ambiental. Além disso, foi registrado que apenas uma minoria das famílias que participam mais ativamente do MFC estabeleceu pastagens em seus lotes, e mesmo assim o fizeram em áreas limitadas. 
Tabela 8. Área e percentagens por modalidade de uso da terra nos lotes do PDS Virola-Jatobá conforme estratégias econômicas dos assentados

\begin{tabular}{|c|c|c|c|c|c|c|c|c|c|c|c|c|c|}
\hline \multirow{2}{*}{ Categoria } & \multirow{2}{*}{$\mathbf{n}$} & & \multirow{2}{*}{$\begin{array}{l}\text { Área do } \\
\text { lote (ha) }\end{array}$} & \multicolumn{2}{|c|}{ Floresta } & \multicolumn{2}{|c|}{ Capoeira } & \multicolumn{2}{|c|}{ Pastagem } & \multicolumn{2}{|c|}{ Cultivo anual } & \multicolumn{2}{|c|}{ Perenes } \\
\hline & & & & $h a$ & $\%$ & $h a$ & $\%$ & ha & $\%$ & $h a$ & $\%$ & $h a$ & $\%$ \\
\hline \multirow{2}{*}{ Agroextrativistas } & \multirow{2}{*}{18} & $\mathrm{~m}$ & 20,21 & 10,47 & 51,20 & 2,73 & 13,37 & 4,22 & 21,23 & 1,81 & 9,35 & 0,97 & 4,85 \\
\hline & & $\mathrm{dp}$ & $(3,4)$ & $(6,6)$ & $(29,4)$ & $(4,4)$ & $(21,7)$ & $(5,2)$ & $(25,4)$ & $(1,4)$ & $(7,7)$ & $(1,3)$ & $(6,6)$ \\
\hline \multirow{2}{*}{ Pecuaristas } & \multirow{2}{*}{3} & $\mathrm{~m}$ & 24,76 & 6,05 & 26,27 & 0,25 & 1,09 & 17,75 & 69,56 & 0,58 & 2,53 & 0,13 & 0,54 \\
\hline & & $\mathrm{dp}$ & $(5,2)$ & $(10,5)$ & $(45,5)$ & $(0,4)$ & $(1,9)$ & $(14,5)$ & $(52,7)$ & $(1,0)$ & $(4,4)$ & $(0,2)$ & $(0,9)$ \\
\hline \multirow{2}{*}{ Diaristas } & \multirow{2}{*}{19} & $\mathrm{~m}$ & & 12,60 & 55,62 & 2,17 & 10,47 & 4,22 & 21,79 & 1,64 & 7,66 & 0,96 & 4,47 \\
\hline & & $\mathrm{dp}$ & $(4,8)$ & $(7,9)$ & $(30,2)$ & $(2,2)$ & $(11,9)$ & $(5,7)$ & $(31,9)$ & $(1,9)$ & $(8,2)$ & $(1,9)$ & $(8,2)$ \\
\hline \multirow{2}{*}{ Agroextrativista-diaristas } & \multirow{2}{*}{8} & $\mathrm{~m}$ & 19,49 & 12,96 & 66,59 & 2,57 & 13,38 & 2,72 & 13,64 & 1,00 & 5,06 & 0,24 & 1,33 \\
\hline & & $\mathrm{dp}$ & $(2,0)$ & $(6,1)$ & $(29,6)$ & $(3,3)$ & $(17,4)$ & $(5,0)$ & $(24,5)$ & $(0,9)$ & $(4,7)$ & $(0,4)$ & $(2,0)$ \\
\hline \multirow{2}{*}{ Assalariados } & \multirow{2}{*}{13} & $\mathrm{~m}$ & 23,36 & 16,54 & 69,20 & 1,79 & 7,51 & 2,67 & 12,73 & 1,62 & 7,36 & 0,73 & 3,20 \\
\hline & & $\mathrm{dp}$ & $(4,1)$ & $(6,4)$ & $(19,2)$ & $(1,5)$ & $(5,1)$ & $(3,7)$ & $(17,7)$ & $(1,4)$ & $(6,5)$ & $(1,0)$ & $(4,6)$ \\
\hline \multirow{2}{*}{ Aposentados/assistidos } & \multirow{2}{*}{15} & $\mathrm{~m}$ & 20,76 & 12,67 & 62,30 & 1,57 & 7,12 & 4,72 & 22,09 & 1,17 & 5,45 & 0,63 & 3,05 \\
\hline & & $\mathrm{dp}$ & $(3,6)$ & $(4,8)$ & $(23,9)$ & $(1,9)$ & $(7,7)$ & $(5,0)$ & $(24,1)$ & $(1,3)$ & $(5,7)$ & $(0,9)$ & $(4,8)$ \\
\hline \multirow{2}{*}{ Total } & \multirow{2}{*}{76} & $\mathrm{~m}$ & 21,30 & 12,56 & 58,21 & 2,09 & 9,93 & 4,43 & 21,19 & 1,47 & 7,10 & 0,75 & 3,58 \\
\hline & & $\mathrm{dp}$ & $(4,1)$ & $(6,9)$ & $(28,3)$ & $(2,8)$ & $(13,9)$ & $(6,1)$ & $(28,1)$ & $(1,4)$ & $(6,9)$ & $(1,3)$ & $(6,0)$ \\
\hline
\end{tabular}

Fonte: Projeto Automanejo, Embrapa Amazônia Oriental (2016).

Tabela 9. Análise estatística da área dos lotes convertida em pastagens, de acordo com estratégia econômica dos assentados do PDS Virola-Jatobá

\begin{tabular}{lccccc}
\hline & Agroextrativista & Pecuarista & Diarista & Assalariado & Aposentado-assist. \\
\hline Pecuarista & $48,33^{*}$ & & & & \\
Diarista & 0,56 & $-47,78^{*}$ & & & \\
Assalariado & $-8,50$ & $-56,84^{* *}$ & $-9,06$ & & \\
Aposentado-assist. & 0,86 & $-47,47^{* *}$ & 0,30 & 9,36 & $-8,45$ \\
Agroextrat.-diarista & $-7,59$ & $-55,93^{* *}$ & $-8,15$ & 0,91 & \\
\hline
\end{tabular}

$\mathrm{F}=2,31 \quad$ Prob $>\mathrm{F}=0,0527$

${ }^{*} p<0,10 ;{ }^{* *} p<0,05 ;{ }^{* *} p<0,01$.

Fonte: Projeto Automanejo, Embrapa Amazônia Oriental (2016).

\section{Considerações finais}

Ante os crescentes investimentos governamentais e internacionais associados à mitigação de mudanças climáticas e contra o desflorestamento na Amazônia, políticas e programas públicos para a conservação ambiental baseados em ações coletivas locais são ainda pouco entendidos e carentes de apoio público (MMA, 2013). Projetos de manejo florestal comunitário constituem uma das poucas alternativas baseadas no uso sustentável de recursos naturais por comunidades locais em assentamentos que combinam reforma agrária e conservação ambiental. Numa gama de possibilidades, para além do binário sucesso-fracasso, sob diferentes pontos de vista, apreende-se uma tendência gradual, mas positiva, à exploração madeireira de impacto reduzido, visando o manejo florestal sustentável (PINTO et al., 2011; SCHULZE et al., 2008). Apesar das dificuldades enfrentadas para a viabilização do manejo florestal comunitário (BOWLER et al., 2012; HAJJAR et al., 2011; HUMPHRIES et al., 2011; MEDINA e POKORNY, 2011; PIKETTY et al., 2015; WALDHOFF e VIDAL, 2015), este permanece como um das poucas alternativas para governança local em contextos sob cobertura florestal (AGRAWAL et al., 2008; BRASIL, 2010; CRONKLETON et al., 2011).

Este estudo foi apoiado na Teoria da Ação Coletiva revisada por Ostrom (2000), que contempla a diversidade de atores e a complexidade de contextos. Foram identificados os diferentes tipos de unidades familiares residentes no PDS Virola-Jatobá, em termos de estratégia econômica, assim como de variáveis contextuais em 
640 - Implicações Sociais, Econômicas e Ambientais de Uma Iniciativa de Manejo Florestal Comunitário em Assentamento na Amazônia Oriental

que as mesmas estão inseridas e que as afetam, como é o caso do momento de chegada no lote e a localização espacial. Também foram identificadas algumas das interações entre os tipos de unidades familiares e essas variáveis contextuais em termos de mobilidade, renda e desflorestamento. No caso empiricamente pesquisado, a AVJ, a Coopaf e o Incra buscam firmar o processo de aprendizado e consolidação de normas sociais para reduzir a rotatividade nos lotes, aumentar a renda familiar e identificar alternativas sustentáveis de uso da terra e recursos naturais. Para tanto, empenharam-se na aprovação de um Plano de Uso comum aos assentados, que contém diretrizes consensuadas para o manejo florestal comunitário e a produção agrícola em nível familiar. Tal plano, contudo, não havia sido aprovado até meados de 2016, sendo mais uma causa de incerteza e insegurança que levou diversas famílias a saírem.

Um aspecto relevante de diferenciação entre as famílias do PDS é o envolvimento das mesmas no processo inicial do assentamento. Nessa fase inicial, os assentados 'pioneiros' vivenciaram experiências de elaboração de normas sociais concretas. Estas famílias ainda hoje exibem maior empenho nas ações coletivas para promover laços comunitários e melhorar suas condições de subsistência. Contudo, a extrema mobilidade observada ao longo dos anos resulta em menor controle na entrada de famílias no PDS, o que é refletido no elevado índice de ocupantes irregulares, que ao final de 2015 alcançava mais de $45 \%$ do total. Ao contrário das famílias analisadas neste estudo, estes ocupantes, via de regra, não compartilham aspectos críticos da normatização do uso da terra no PDS, especialmente no momento de sua chegada. Torna-se, portanto, essencial que procedimentos na seleção, inserção e formação de assentados sejam revisados de forma a empoderar as organizações locais, limitando a ocupação irregular.

Foi constatado que os produtores "pioneiros" apresentaram, proporcionalmente, menor desmatamento em seus lotes, apesar do maior número de anos de uso. Em seus lotes, registrou-se qualitativamente fortes laços de reciprocidade e autonomia, especialmente em torno do cultivo da roça. Registrou-se etnograficamente fortes indícios de que a roça constitui espaço social favorável ao fortalecimento das normas sociais internas, que consolidariam ação coletiva também em relação ao MFC. Nesse sentido, em 2016, a AVJ e seus colaboradores, ao cumprirem as exigências para o licenciamento das atividades agrícolas nas áreas de uso alternativo, tomaram a iniciativa de inventariar todas as árvores das áreas de suas futuras roças com intuito de seu aproveitamento, redobrando esforços para articular melhorias da roça com operações do MFC. No entanto, apesar de bem recebida, a morosidade dos processos burocráticos no Incra e Semas impediram a efetividade da iniciativa.

Os dados obtidos indicam, contudo, que a rotatividade dos ocupantes nos lotes não explica o desflorestamento a partir do limite de três ocupantes sucessivos. Condições peculiares de posse da terra características aos PDS, combinadas com problemas infraestruturais (falta de estradas trafegáveis e outras formas de acesso), insuficiência de prestadores de assistência técnica e dificuldades do meio físico (topografia acentuada e baixa fertilidade do solo), serviram, em princípio, como mecanismos de triagem para repelir famílias não comprometidas. Inicialmente, a confiança na CPT e movimentos sociais aliados contribuiu para que um número crescente de famílias aderisse à modalidade. Mesmo assim, muitas destas famílias gradualmente deixaram a terra, vencidas pela falta de condições para produção economicamente viável. Durante o moroso processo de consolidação de novas lideranças no PDS, uma orientação individual prevaleceu entre o grupo mais numeroso de famílias que se instalou a partir de 2008, os denominados 'novatos' (MENDES et al., 2012). Mesmo assim, passados anos de ajustes e negociações, e tendo suas ocupações regularizadas pelo Incra, tais famílias parecem ter chegado a uma pactuação de normas que permite a convivência. $\mathrm{O}$ mesmo processo repete-se, porém, de forma ainda mais pronunciada, com o recente fluxo de moradores, ainda irregulares, que adentraram o PDS nos últimos dois anos, sem consentimento do Incra ou da Associação, e que adotam postura cada vez menos compromissada com as normas de uso de recursos inerente ao PDS.

Para que normas sociais internas ao PDS se consolidem, há que se encontrar instituições comuns aos distintos grupos. Em trabalho de campo na busca destas respostas, esta pesquisa detectou a resiliência de determinados institutos camponeses em torno da roça, como instituição agregadora e mantenedora de relações de reciprocidade ${ }^{20}$ e autonomia necessárias

20. A roça é uma instituição do campesinato fundada em normas sociais que estabelecem relações de reciprocidade $(\mathrm{N}$. PORRO, 1997). Para a conceituação de reciprocidade ver Mauss (1954). 
às ações coletivas requeridas no MFC. Os dados obtidos não permitem a comprovação de hipóteses sobre causas isoladas de evasão; porém, na pesquisa empírica em campo, evidenciam-se casos que indicam que não são os recursos advindos da exploração madeireira, mas, sim, a incorporação destes na instituição fundante, a roça, que define a continuidade de modos de vida locais, e consequentemente de patamares desejáveis de renda, mobilidade e desmatamento. Assim, é premente estabelecer diretrizes que compatibilizem o acesso e uso de recursos naturais com as exigências da produção agropecuária calcada em bases tradicionais.

Concluímos que, para a efetividade do manejo florestal comunitário e do PDS como um todo, a consolidação de normas sociais internas, que articulem o cultivo da roça com o manejo florestal, é condição essencial e prioritária. Para cumprir esse condicionante, as organizações locais proponentes do MFC (e o governo como ente promotor) devem apreender quais variáveis contextuais incentivam, e quais limitam, cada um dos segmentos divergentes na criação e adoção das normas sociais a serem compartilhadas. No enfoque dado, conclui-se que uma das formas de expressão dessas normas seria o Plano de Uso do assentamento, mecanismo necessário para a emissão do Contrato de Concessão de Direito Real de Uso (CCDRU) aos beneficiários, e que, espera-se que uma vez aprovado, seja instrumento para ação coletiva no controle da mobilidade, melhoria de renda e contenção do desmatamento.

\section{Referências}

ALENCAR, A. et al. Desmatamento nos assentamentos da Amazônia: histórico, tendências e oportunidades. Brasília, IPAM, 2016, 93 p.

BARBIERI, A. F. Mobilidade populacional, meio ambiente e uso da terra em áreas de fronteira: uma abordagem multiescalar. Revista Brasileira de Estudos de População, v. 24, n. 2, p. 225-246, 2013.

BENATTI, J. H. A criação de unidades de conservação em áreas de apossamento de populações tradicionais. Novos cadernos NAEA, v. 1, n. 2, 2014.

BOWLER, D. E. et al. Does community forest management provide global environmental benefits and improve local welfare? Frontiers in Ecology and the Environment, v. 10, n. 1, p. 29-36, 2012.
BRASIL. Ministério do Meio Ambiente. Serviço Florestal Brasileiro. Plano anual de manejo florestal comunitário e familiar: período 2011. Brasília, SFB, 2010. 148 p.

CAMPARI, J. S. Challenging the turnover hypothesis of Amazon deforestation: evidence from colonization projects in Brazil. Tese (Doutorado) - University of Texas, Austin, 2002.

. The economics of deforestation in the Amazon: dispelling the myths. Northampton (MA): Edward Elgar Publishing, 2005.

CRONKLETON, P., BRAY, D. B. e MEDINA, G. Community forest management and the emergence of multi-scale governance institutions: lessons for REDD+ development from Mexico, Brazil and Bolivia. Forests, v. 2, n. 2, p. 451-473, 2011.

DE SARTRE, X. A. et al. Mobilidades geográficoprofissionais de duas gerações de agricultores familiares assentados na Amazônia oriental. Boletim do Museu Paraense Emílio Goeldi Ciências Humanas, v. 11, n. 1, p. 17-32, jan./abr. 2016.

ESRI. ArcGIS: a complete integrated system. Disponível em: < http://www.esri.com/software/arcgis/>. Acesso: 06 jul. 2015.

GARCIA FILHO, D. P. et al. Metodologia de análise diagnóstico de sistemas agrários. Convênio INCRA/FAO, 1997. Disponível em: < http://www.incra.gov.br/media/ reforma_agraria/guia_metodologico.pdf $>$. Acesso: 22 abr. 2016.

GODOI, E. P., MENEZES, M. A. e ACEVEDO MARIN, R. E. Introdução. In: Diversidade do campesinato: expressões e categorias. Vol. I. Construções identitárias e sociabilidades. São Paulo: Editora UNESP; Brasília: NEAD, 2009, p. 23-36.

GUZMÁN, E. S. e MOLINA, M. G. Da nova tradição dos estudos camponeses à Agroecologia. In: Sobre a evolução do conceito de campesinato. São Paulo, Via Campesina / Expressão Popular, 2005.

HAJJAR, R. et al. Framing community forestry challenges with a broader lens: case studies from the Brazilian Amazon. Journal of Environmental Management, v. 92, n. 9, p. 2159-2169, 2011.

HUMPHRIES, S. et al. Are community-based forest enterprises in the tropics financially viable? Case studies from the Brazilian Amazon. Ecological Economics, v. 77, p. 62-73, 2012.

INPE/DPI - Instituto Nacional de Pesquisas Espaciais/ Divisão de Processamento de Imagens. Spring: sistema de processamento de informações georreferenciadas. 
642 - Implicações Sociais, Econômicas e Ambientais de Uma Iniciativa de Manejo Florestal Comunitário em Assentamento na Amazônia Oriental

Disponível em: <http://www.dpi.inpe.br/spring $>$. Acesso: 11 maio 2015.

LE TOURNEAU, F. M. e BURSZTYN, M. Assentamentos rurais na Amazônia: contradições entre a política agrária e a política ambiental. Ambiente $\mathcal{E}$ Sociedade, v. 13, n. 1, p. 111-130, 2010.

LIMA, D. e POZZOBON, J. Amazônia socioambiental: sustentabilidade ecológica e diversidade social. Estudos avançados, v. 19, n. 54, p. 45-76, 2005.

LUDEWIGS, T. Land-use decision making, uncertainty and effectiveness of land reform in Acre, Brazilian Amazon. Ph.D. Dissertation. Indiana University, Bloomington (IN), 2006.

et al. Agrarian structure and land-cover change along the lifespan of three colonization areas in the Brazilian Amazon. World Development, v. 37, n. 8, p. 1348-1359, 2009.

MAUSS, M. The Gift. Forms and functions of exchange in archaic societies. Traduzido por Ian Cunnison. Londres, 1954.

MDA/INCRA - Ministério do Desenvolvimento Agrário/Instituto Nacional de Colonização e Reforma Agrária. Metodologia para implantação dos Projetos de Desenvolvimento Sustentável - PDS. Brasília, Superintendência Nacional do Desenvolvimento Agrário, Coordenação Geral Técnica, 2006.

MEDINA, G. e POKORNY, B. Avaliação financeira do manejo florestal comunitário. Novos Cadernos NAEA, v. 14, n. 2, p. 25-26, dez. 2011.

MENDES, J. F. O direito vivo na luta pela terra. Curitiba: Editora Appris, 2015.

, PORRO, N. S. M. e SHIRAISHI-NETO, J. A "ambientalização" dos conflitos sociais no PDS Virola Jatobá no município de Anapu, Estado do Pará. In: Anais do $36^{\circ}$ Encontro Anual da ANPOCS. 21-25 outubro 2012. Águas de Lindóia, SP, Brasil. Disponível em: <http:// portal.anpocs.org/portal/index.php?option $=$ com docman\&task $=$ doc_view\&gid $=7861 \&$ Itemid $=217>$. Acesso em: 27 jan. 2016.

MMA - Ministério do Meio Ambiente. Plano de Ação para prevenção e controle do desmatamento na Amazônia Legal (PPCDAM): $3^{\text {a }}$ fase (2012-2015) pelo uso sustentável e conservação da floresta. Brasilia, Ministério do Meio Ambiente e Grupo Permanente de Trabalho Interministerial. Brasília: MMA, 2013, 174 p.

OSTROM, E. Collective action and the evolution of social norms. Journal of Economic Perspectives, v. 14, n. 3, p. 137-158, 2000.
PIKETTY, M-G. et al. Annual cash income from community forest management in the Brazilian Amazon: Challenges for the future. Forests, v. 6, n. 11, p. $4228-4244,2015$.

PINTO, A., AMARAL, P. e AMARAL NETO, M. Iniciativas de manejo florestal comunitário e familiar na Amazônia brasileira 2009/2010. Belém, Imazon - IEB, 2011, 84 p.

PORRO, N. S. M. Changes in perception of development and conservation. Dissertação (Mestrado em Estudos Latinoamericanos) - Center for Latin American Studies, University of Florida, Gainesville (FL), 1997.

PORRO, R. et al. Collective action and forest management: institutional challenges for the environmental agrarian reform in Anapu, Brazilian Amazon. International Forestry Review, v. 17, n. 1, p. 20-37, 2015.

POTEETE, A. e OSTROM, E. Heterogeneity, group size and collective action: the role of institutions in forest management. Development and Change, v. 35, n. 3, p. $435-461,2004$

REYNAL, V. D. et al. Agriculturas familiares $e$ desenvolvimento em frente pioneira amazônica. Paris/Belém/ Pointe-à-Pitre, GRET, LASAT/CAT, DAT/UAG, 1995.

SABLAYROLLES, P. et al. O manejo florestal sustentável como alternativa na reprodução social de comunidades no oeste paraense? In: HILDEMBERG CRUZ et al. (Eds.). Relação empresa/comunidade no contexto do manejo florestal comunitário e familiar: uma contribuição do projeto Floresta em Pé. Belém: IBAMA-MMA, 2011. p. 149-170.

SABOURIN, E. Organizações e sociedades camponesas, uma leitura através da reciprocidade. Porto Alegre: Ed. da UFRGS, 2011.

SCHULZE, M., GROGAN, J. e VIDAL, E. O manejo florestal como estratégia de conservação e desenvolvimento socioeconômico na Amazônia: quanto separa os sistemas de exploração madeireira atuais do conceito de manejo florestal sustentável. In: BENSUSAN, N. e ARMSTRONG, G. (Coords.). O manejo da paisagem e a paisagem do manejo. Brasília: Instituto Internacional de Educação do Brasil, 2008. p. 163-203.

SHANIN, T. A definição de camponês: conceituações e desconceituações - o velho e o novo em uma discussão marxista. Revista NERA, ano 8, n. 7, p. 1-21, 2005. [Original: A definição de camponês: conceituações e desconceituações. Novos Estudos Cebrap, n. 26, p. 43-80, 1980]. 
SIST, P. et al. Populations rurales et préservation de la forêt amazonienne brésilienne. Le Flamboyant, 2010 - agritrop. cirad.fr

THIOLLENT, M. Metodologia da pesquisa-ação. 12. ed. Cortez, 2003.

VELHO, O. G. Frentes de expansão e estrutura agrária: estudo do processo de penetração numa área da Transamazônica. Rio de Janeiro: Zahar, 1972.
WALDHOFF, P. e VIDAL, E. Community loggers attempting to legalize traditional timber harvesting in the Brazilian Amazon: an endless path. Forest Policy and Economics, v. 50, p. 311-318, 2015.

WATRIN, O. S., GERHARD, P. e MACIEL, M. N. M. Dinâmica do uso da terra e configuração da paisagem em antigas áreas de colonização de base econômica familiar, no nordeste do estado do Pará. Geografia, v. 34, n. 3, p. 455-472, set./dez. 2009.

Todo o conteúdo deste periódico, exceto onde estiver identificado, está licenciado sob uma Licença Creative Commons (cc by 4.0). 
